\title{
Directly modulated active distributed reflector distributed feedback lasers over wide temperature range operation $\left(-40\right.$ to $\left.85^{\circ} \mathrm{C}\right)$
}

\author{
Gonghai Liu (刘功海), Gongyuan Zhao (赵龚媛), Gong Zhang (张 功), \\ Qiaoyin Lu (陆巧银), and Weihua Guo (国伟华)* \\ Wuhan National Laboratory for Optoelectronics \& School of Optical and Electronic Information, \\ Huazhong University of Science and Technology, Wuhan 430074, China \\ *Corresponding author: guow@mail.hust.edu.cn \\ Received December 8, 2019; accepted March 1, 2020; posted online May 12, 2020
}

\begin{abstract}
We experimentally demonstrated that the distributed feedback (DFB) lasers with the active distributed reflector achieved a $25.8 \mathrm{~Gb} / \mathrm{s}$ operation over a wide temperature range of -40 to $85^{\circ} \mathrm{C}$. The DFB lasers can achieve additional feedback from an active distributed reflector with accurately controlled phase, and single-mode yields are not related to the position of cleave. The threshold currents of the fabricated laser are $6 \mathrm{~mA}$ and $20 \mathrm{~mA}$ at $-40^{\circ} \mathrm{C}$ and $85^{\circ} \mathrm{C}$, respectively. The side mode suppression ratio of the fabricated laser is above $50 \mathrm{~dB}$ at all temperatures. Transmissions of $25.8 \mathrm{~Gb} / \mathrm{s}$ after $10 \mathrm{~km}$ single-mode fibers with clear eye openings and less than $0.8 \mathrm{~dB}$ power penalty over a wide temperature range have been demonstrated as well.

Keywords: distributed feedback laser; wide temperature range; active distributed reflector; directly modulated laser.

doi: 10.3788/COL202018.061401.
\end{abstract}

Data traffic has been continually growing since the late 1990s. This capacity growth in data traffic demands an increase in data rates, and thus demands of high-speed and cost-effective transceivers have continually increased. The $1.3 \mu \mathrm{m}$ directly modulated lasers (DMLs) have been greatly used for the Ethernet, datacenter, metro access, enterprise embracing, and the $5 \mathrm{G}$ prequel. Multichannel configuration of DMLs is a cost-effective and efficient way to realize large capacity transmission, such as 100 Gbit Ethernet $(4 \times 25 \mathrm{~Gb} / \mathrm{s})^{[1-4]}$. However, as an increase in the number of channels causes an increase in power consumption and footprints of optical modules, these lasers need to operate at high rates without a power consuming electric cooler, because the amount of heat they generate limits the quantity of optical interfaces assembled on board. Therefore, high-speed DMLs with wide temperature range operation are a more efficient and cost-effective choice to realize compact and low-power-consumptive optical transmitters on high-density optical interfaces of multichannel configuration. The operating temperature range of the existing distributed feedback (DFB) laser included commercial temperatures $\left(0-70^{\circ} \mathrm{C}\right)$ and industrial temperatures $\left(-40-85^{\circ} \mathrm{C}\right)^{[5-9]}$. The industrial temperature demands conditions for a semiconductor laser but has higher utility value.

For increasing high transmission rates of directly modulated DFB lasers, the modulation bandwidth needs to improve as much as possible. It is an efficient method to increase the modulation bandwidth by improving the relaxation oscillation frequency $f_{r}$. Generally, the $3 \mathrm{~dB}$ modulation bandwidth $f_{3 \mathrm{~dB}}$ is about $1.55 f_{r}$ if the effect of the parasitic parameter can be ignored ${ }^{[5-8]}$. The relaxation oscillation frequency $f_{r}$ increases with increased injection current $I_{0}$ or internal optical density, which is usually restricted by the thermal saturation and maximum power consumption of the laser. The relaxation oscillation frequency $f_{r}$ can be related to the following formula ${ }^{[6-8]}$ :

$$
f_{r}=\sqrt{\frac{v_{g}}{4 \pi^{2}} \frac{\Gamma_{\mathrm{MQW}}}{W N_{W} L_{W}} \frac{\eta_{i}}{L_{c}}\left(I_{0}-I_{t h}\right) \frac{\mathrm{d} g}{\mathrm{~d} n}},
$$

where $\mathrm{d} g / \mathrm{d} n, I_{0}, I_{t h}, \eta_{i}, W$, and $L_{c}$ stand for the material differential gain, the injection current, the threshold current, injection efficiency, the width, and the length of the active section, respectively, and $v_{g}$ is the group velocity. $N_{W}$ and $L_{W}$ are the number and thickness of quantum well layers, respectively. According to Eq. (1), it can be found that $f_{r}$ is roughly related to $\mathrm{d} g / \mathrm{d} n, I_{t h}$, and $L_{c}$. The $I_{t h}$ and $L_{c}$ must be decreased to increase $f_{r}$ when $I_{0}$ keeps the proper value. However, it is quite challenging to make short active sections with low threshold current because a short active region also means small round-trip gain, which leads to a high threshold current. This is done by providing additional feedback to keep threshold current suitable. What is more, short-cavity lengths $(<150 \mu \mathrm{m})$ can significantly increase the complexity of fabrication, such as the chemical mechanical polishing process and cleavage process.

There are many methods reported to achieve short active region lengths with an applicable threshold current, such as DFB lasers coated with one high-reflection (HR) cleaved facet and DFB lasers integrated with passive distributed Bragg reflector (DBR) mirrors $-\underline{[7,-14]}$. DFB lasers 
with one cleaved facet HR coated can effectively reduce the threshold current when a short active region length is being used. Unfortunately, the reflection phase at the HR coated facet cannot be accurately controlled because of the limitation of cleave accuracy. The mode of these DFB lasers was hard to control, and the single-mode stability was seriously deteriorated. The DFB lasers integrated with passive DBR mirrors can achieve additional feedback to reduce the threshold gain from the DBR mirrors. The additional feedback with an accurately controlled reflection phase is due to the existence of a grating; thus, they have $100 \%$ single-mode yield in theory. However, the fabrication complexity of DFB lasers integrated with passive DBR mirrors significantly increases due to butt-joint regrowth, especially when aluminumcontaining multi-quantum wells (MQWs) are used for obtaining strong electron confinement and high differential gain over a wide temperature range. Because aluminum-containing compound semiconductor materials are susceptible to oxidation, the reliability and quality of the materials are reduced ${ }^{[15,16]}$.

In this Letter, we have experimentally achieved wide temperature range operation $\left(-40-85^{\circ} \mathrm{C}\right)$ of the DFB laser with an active distributed reflector (ADR) for obtaining a short cavity with reasonable threshold gain. The ADR has the same MQWs and grating period as the active region, as shown in the Fig. 1(a). The wafer is based on an n-InP substrate with high Si doping. The InGaAlAs-MQWs consist of eight compressively strained wells and nine tensile strained barriers. Two thin separate confinement heterostructure ( $\mathrm{SCH}$ ) layers are on the top and bottom sides of the MQWs. A separate $80 \mathrm{~nm}$ InGaAsP layer for the grating was grown on the upper $\mathrm{p}$ side. The active section

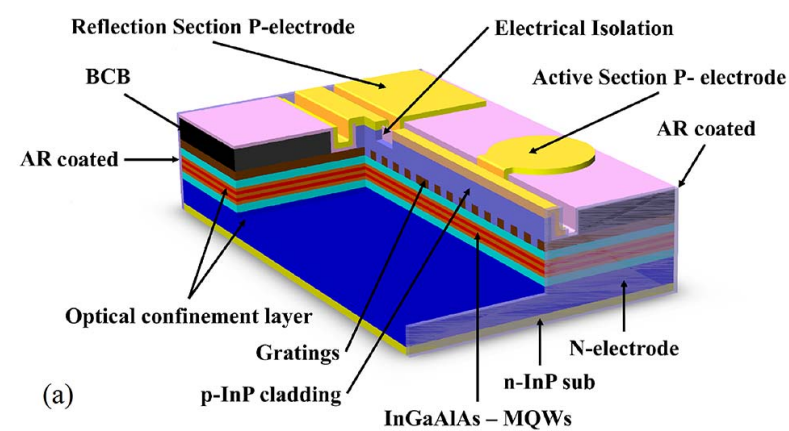

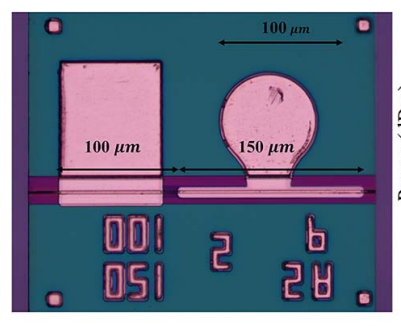

(b)

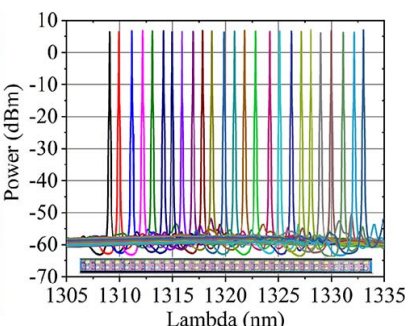

(c)
Fig. 1. (a) Structure diagram of the ADR-DFB lasers, (b) microscope photograph of the fabricated laser, and (c) measured optical spectrum of twenty-five adjacent ADR-DFB lasers on an $8 \mathrm{~mm}$ cleave bar. has a $\lambda / 4$ shifted grating with the phase shift positioned closer to the reflection section $\frac{[17]}{-}$. The parasitic capacitance was reduced by forming the active section $\mathrm{P}$ electrode on the benzocyclobutene (BCB). The front and rear cleaved facets were both anti-reflection (AR) coated. The microscope image of the fabricated device is shown in Fig. 1(b). The active region length of the fabricated laser is $150 \mu \mathrm{m}$, and a $100 \mu \mathrm{m}$ long ADR followed. The grating coupling coefficient is estimated at about $130 \mathrm{~cm}^{-1}$ by the amplified spontaneous emission (ASE) spectrum of the DFB laser with a uniform grating. The electrical isolation resistance between two sections is about $18 \mathrm{k} \Omega$, which was obtained by partially etching off the highly p-doped layers. Although the electrode of the ADR has been fabricated, it is always under the floating status when the laser is working.

In Ref. [18], we have demonstrated that the ADR can be clamped on near transparency by the photon from the laser itself, because the photon-generated carriers will mainly be removed through radiation recombination at a relatively low rate when the ADR is at floating status. Therefore, it can provide additional feedback to the laser to reduce the threshold current, similar to the DBR mirrors as mentioned above $e^{[17-21]}$. The ADR-DFB laser also has $100 \%$ single-mode yield in theory, because the phase of additional feedback from the ADR is controlled by the grating pitch and is not related to the position of cleave. In order to verify the independence of the position of cleave, we measured the optical spectrum of twenty-five adjacent ADR-DFB lasers on an $8 \mathrm{~mm}$ cleave bar, as shown in Fig. 1(c). The ADR-DFB lasers have excellent single-mode stability, and the single-mode suppression ratios (SMSRs) of twenty-five adjacent lasers are all above $55 \mathrm{~dB}$. The error of wavelength controlling of twenty-five adjacent lasers shown in Fig. 1(c) is below $0.32 \mathrm{~nm}$. These results show that the single-mode stability and wavelength controlling reliability of the ADR-DFB laser have been improved compared to using cleaved facet HR coating to achieve short active region lengths. The fabrication process of the ADR-DFB laser we used is similar to standard DFB lasers without special processes such as butt-joint regrowth. Therefore, the ADR-DFB laser is a competent and low-cost choice for realizing compact and low-power-consumptive optical transmitters on highdensity optical interfaces of multichannel configuration.

Figure 2(a) shows the measured temperature dependence of the light-current (LI) curve of the fabricated ADR-DFB laser. The threshold currents at $-40,20,50$, and $85^{\circ} \mathrm{C}$ were $6,8,12.1$, and $20 \mathrm{~mA}$, respectively. The values for slope efficiency are $0.45,0.37,0.31$, and $0.2 \mathrm{~W} / \mathrm{A}$ before the thermal effect starts to dominate at $-40,20,50$, and $80^{\circ} \mathrm{C}$, respectively. An optical output power of about $5 \mathrm{~mW}$ with a current of $50 \mathrm{~mA}$ at $85^{\circ} \mathrm{C}$ was obtained.

Measured optical spectra of the ADR-DFB laser biased at $60 \mathrm{~mA}$ are shown in Fig. 3(a). Single-mode spectra of the laser exhibit high SMSRs of more than $50 \mathrm{~dB}$ in the temperature range from -40 to $85^{\circ} \mathrm{C}$. These single-mode 

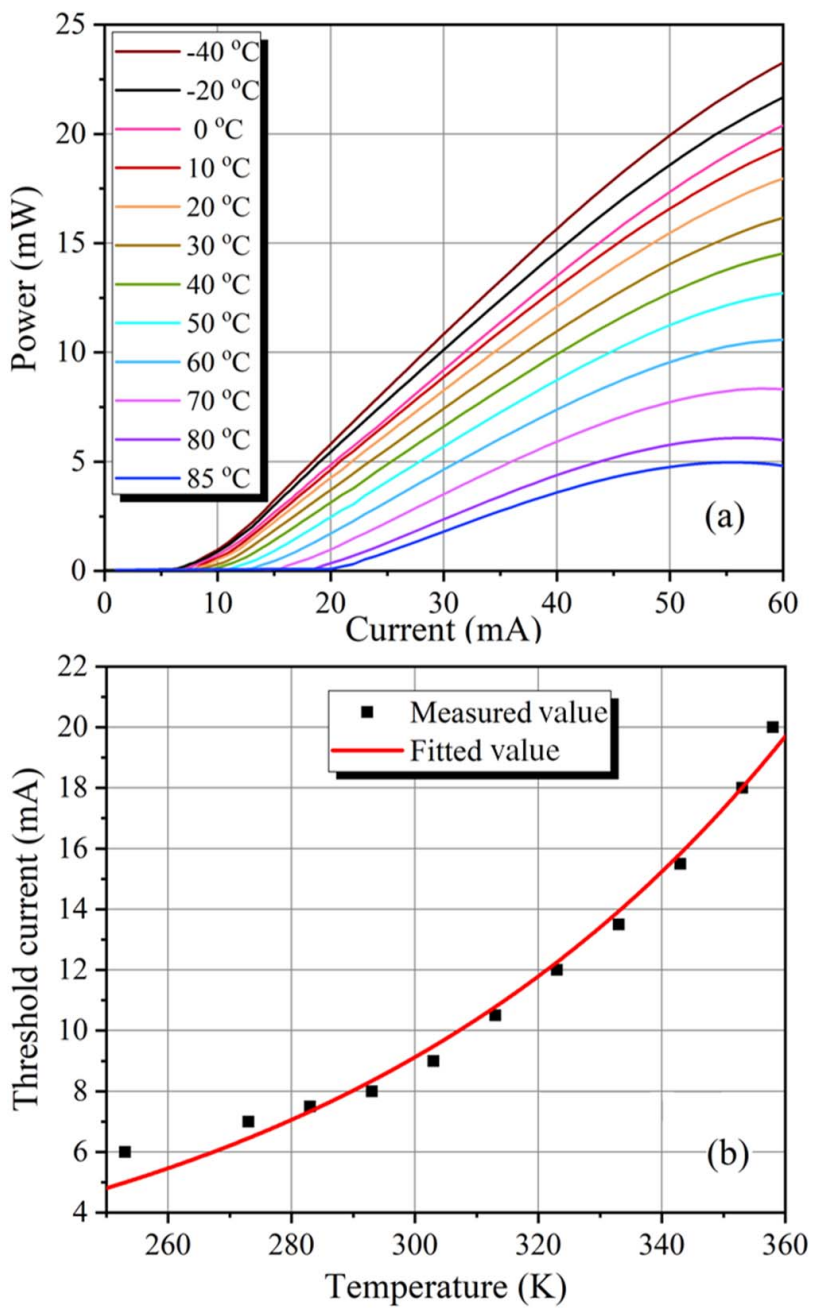

Fig. 2. (a) Light-current characteristics of the ADR-DFB laser over a wide temperature range of $-40-85^{\circ} \mathrm{C}$ and (b) the characteristic temperature of the ADR-DFB laser.

spectra with high SMSRs over a wide temperature range are due to the careful design of the phase-shift structure ${ }^{[17]}$. The lasing wavelength of the ADR-DFB laser is $1329 \mathrm{~nm}$, and the wavelength peak of the active region is $1334 \mathrm{~nm}$ at $20^{\circ} \mathrm{C}$. The wavelength detuning of the lasing wavelength and the gain peak wavelength is about $-5 \mathrm{~nm}$ at $20^{\circ} \mathrm{C}$. The negative value of the wavelength detuning can get a larger differential gain of the active region, but a larger negative value of the detuning generally causes an excess increase of the threshold current. Thus, the laser with a wide temperature range operation needs to select appropriate wavelength detuning to accommodate the operation temperature change. Figure $\underline{3(\mathrm{~b})}$ shows the lasing wavelength of the ADR-DFB laser varies with the measured ambient temperature; the slope is about $0.092 \mathrm{~nm} /{ }^{\circ} \mathrm{C}$. According to the lasing wavelength shift with the drive current, it is estimated that the junction temperature rises over $22^{\circ} \mathrm{C}$ when the laser drive current is $60 \mathrm{~mA}$.

The ADR-DFB laser was bonded onto an AlN carrier that has a $40 \Omega$ resistor within the coplanar waveguide for impedance matching. In order to avoid any parasitic
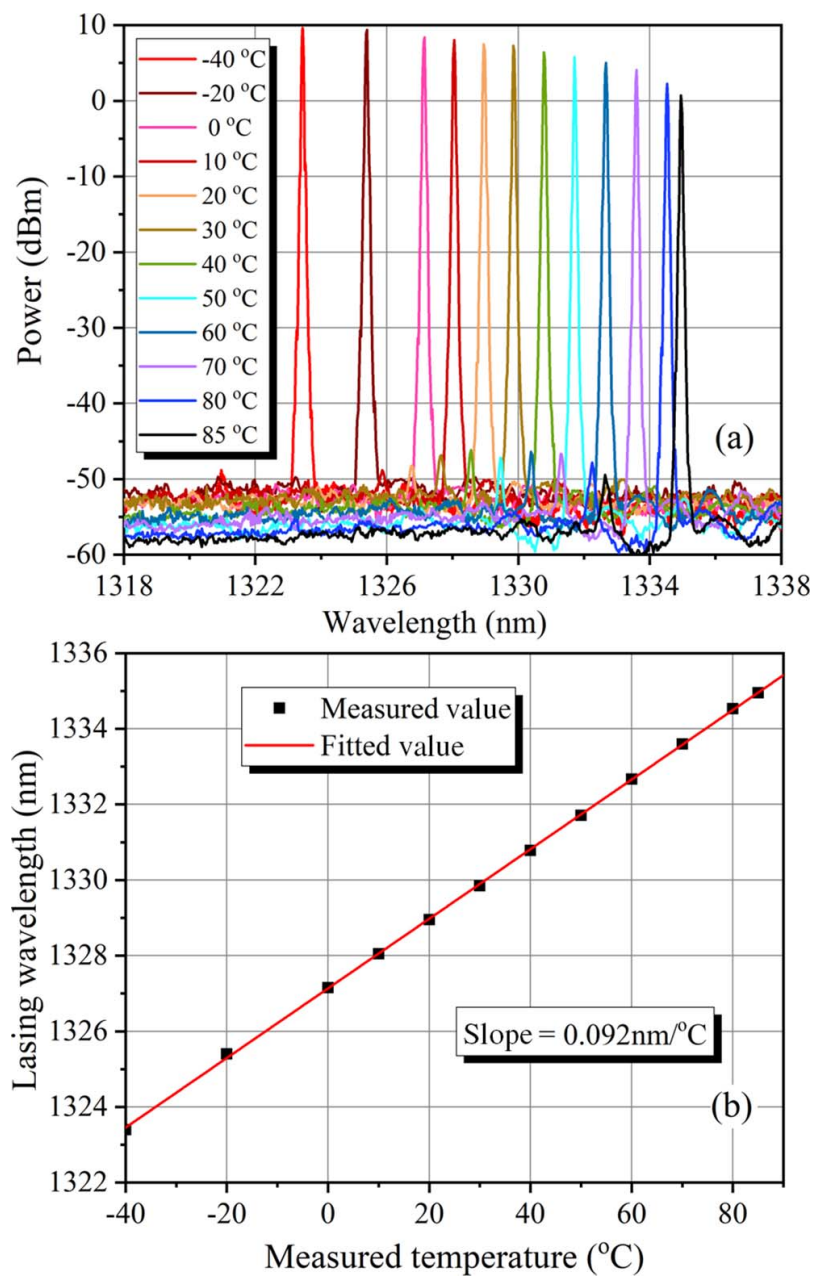

Fig. 3. (a) Measured optical spectra of the ADR-DFB laser under the drive current of $60 \mathrm{~mA}$ over a wide temperature range of $-40-85^{\circ} \mathrm{C}$ and (b) the varied lasing wavelength of the ADRDFB laser with the measured ambient temperature.

influence, the bonding wire length needs to be minimized. Small signal frequency response of the ADR-DFB lasers was obtained. The $3 \mathrm{~dB}$ bandwidths of the fabricated laser with $60 \mathrm{~mA}$ drive current at $-40,20,50$, and $85^{\circ} \mathrm{C}$, were $23.5,23.0,20.1$, and $15.0 \mathrm{GHz}$, respectively. The bandwidths of the fabricated laser under a $60 \mathrm{~mA} \mathrm{CW}$ drive current approach saturation because the self-heating becomes large, as shown in the Fig. $\underline{4}$.

As mentioned above, it was universally accepted that shortening the length of the active region was an efficient method to improve frequency relaxation oscillations, $f_{r}$. But, for a short-cavity laser chip, the thermal effect becomes a key influencing factor to increasing $f_{r}$ because series resistance and thermal resistance simultaneously increase. The thermal effect of the ridge waveguide highspeed laser is more severe because the thermal conductivities of $\mathrm{BCB}$ are lower than that of the $\mathrm{InP}$ and SiN. Therefore, the thermal resistance of a short active region laser is a critical parameter for performance. As shown in Fig. $\underline{5}$, the thermal resistance of ADR-DFB laser we fabricated is about $247 \mathrm{~K} / \mathrm{W}$, and the thickness of the chip is 


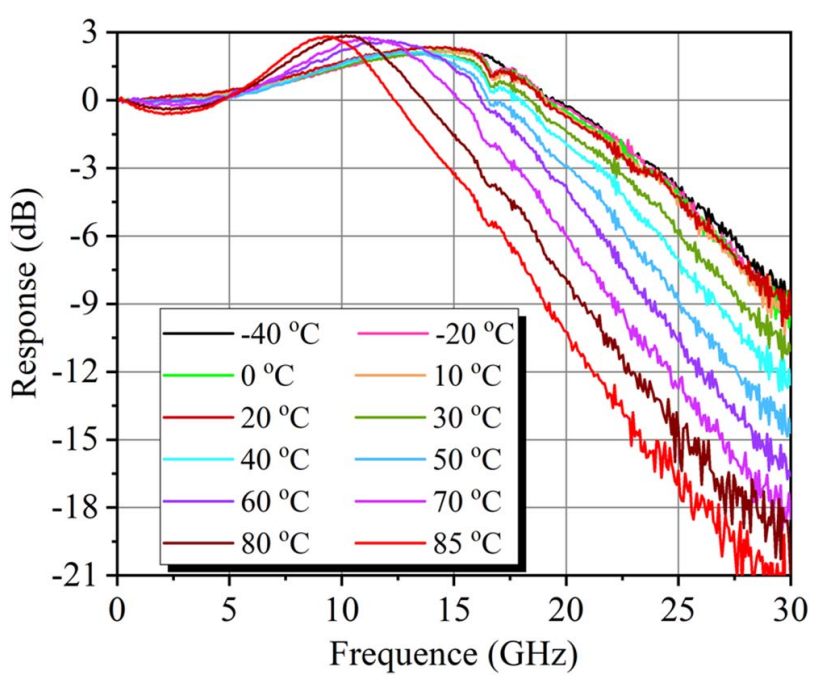

Fig. 4. Electro/optical (E/O) response of the fabricated ADRDFB laser with the bias current of $60 \mathrm{~mA}$ over a wide temperature range of $-40-85^{\circ} \mathrm{C}$.

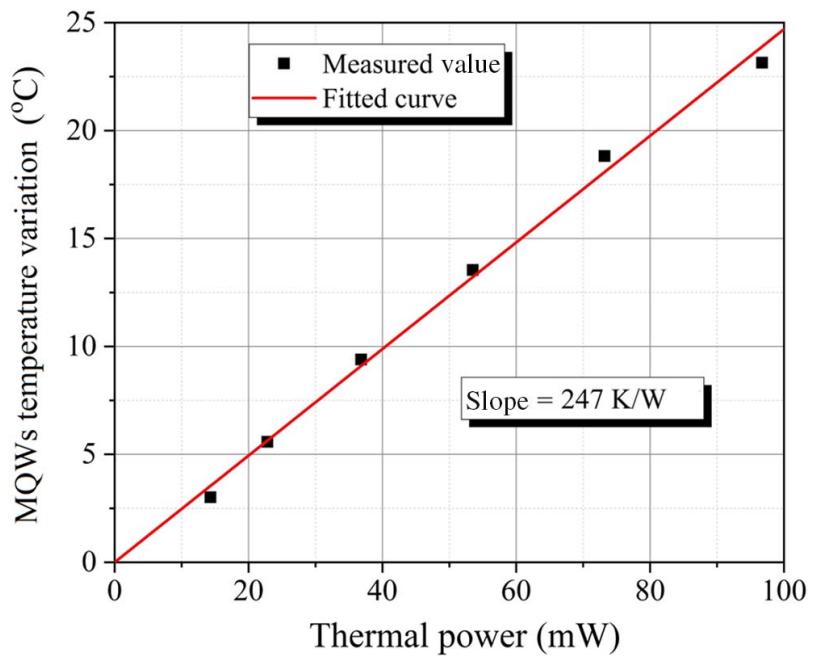

Fig. 5. Thermal resistance of the ADR-DFB laser.

about $120 \mu \mathrm{m}$ by manual polishing. The MQWs' temperature variation is extracted by the lasing wavelength variation. The thermal resistance can be decreased by reducing the thickness of the chip and thickening the metal of the $\mathrm{P}$ electrode.

Then, the eye diagram of the ADR-DFB laser was measured using a pulse-pattern generator with a $25.8 \mathrm{~Gb} / \mathrm{s}$ non-return-to-zero (NRZ) signal having a $2^{31}-1$ pseudorandom bit sequence. The $25.8 \mathrm{~Gb} / \mathrm{s}$ NRZ electrical waveform load to the ADR-DFB laser is shown in Fig. 6(a). Figures $\underline{6(\mathrm{~b})}-\underline{6(\mathrm{~g})}$ show the bias current $I_{b}$, the applied modulation current $I_{p p}$, and the back-to-back (BTB) and the $10 \mathrm{~km}$ single-mode fiber (SMF)-transmitted $25.8 \mathrm{~Gb} / \mathrm{s}$ eye diagrams at $-40,-20,0,20,40,60$, and $85^{\circ} \mathrm{C}$, respectively. Clear eye diagrams were achieved at all temperatures, and dynamic extinction ratios of all eye diagrams were more than $5 \mathrm{~dB}$.

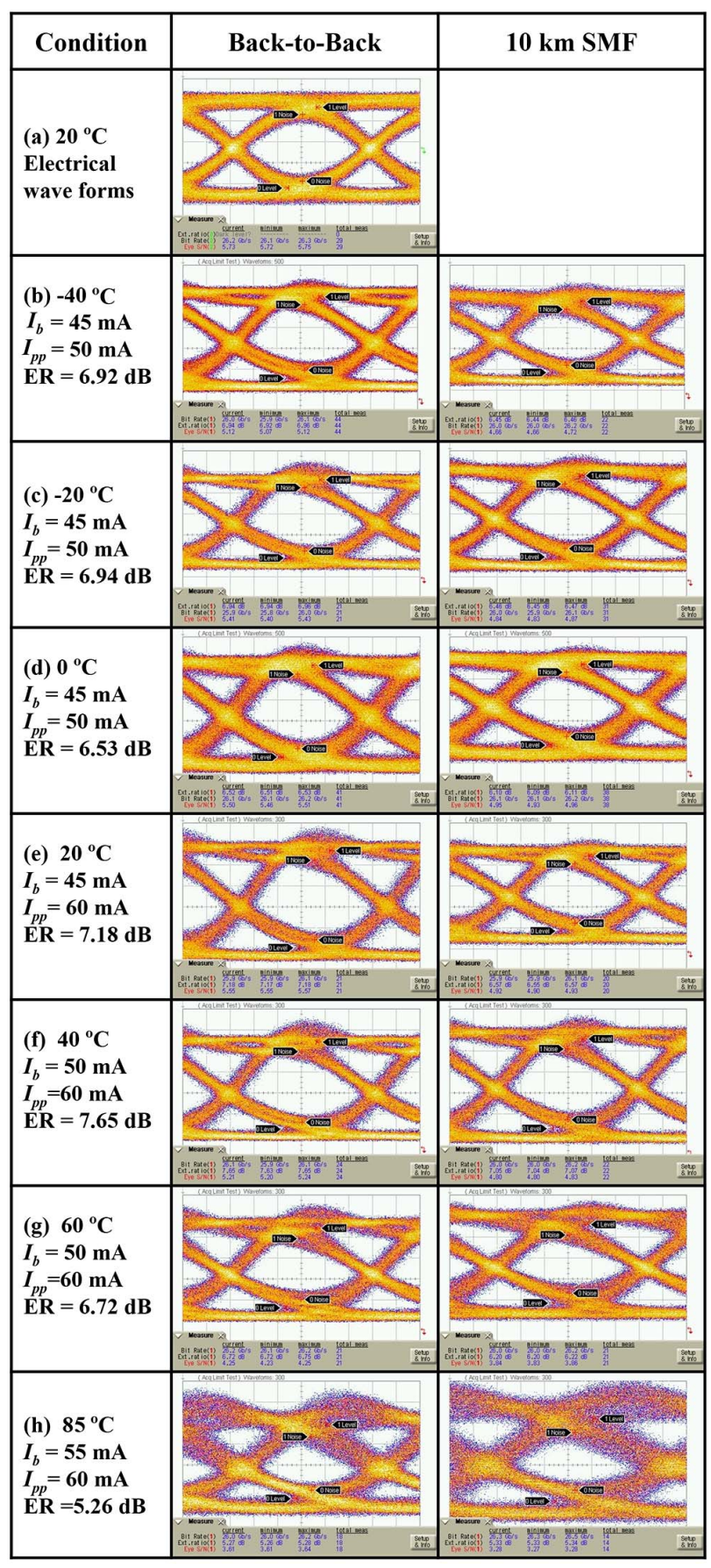

Fig. 6. (a) $25.8 \mathrm{~Gb} / \mathrm{s}$ eye diagrams of the electrical wave waveforms and $25.8 \mathrm{~Gb} / \mathrm{s}$ eye diagrams of measured BTB and after $10 \mathrm{~km}$ SMF transmission at (b) $-40^{\circ} \mathrm{C}$, (c) $-20^{\circ} \mathrm{C}$, (d) $0^{\circ} \mathrm{C}$, (e) $20^{\circ} \mathrm{C}$, (f) $40^{\circ} \mathrm{C},(\mathrm{g}) 60^{\circ} \mathrm{C}$, and (h) $85^{\circ} \mathrm{C}$.

Finally, we also measured the $25.8 \mathrm{~Gb} / \mathrm{s}$ transmission characteristics with an NRZ pseudo-random binary sequence of $2^{31}-1$. Figure $\underline{7}$ shows the bit error rate (BER) characteristics for BTB configuration and $10 \mathrm{~km}$ SMF transmissions at $-40,-20,0,20,40,60$, and $85^{\circ} \mathrm{C}$, respectively. As shown in Fig. $\underline{7}$, an error-free operation was obtained for $10 \mathrm{~km}$ SMF transmissions at all temperatures. We can find that the power penalty over the $10 \mathrm{~km}$ SMF transmission is less than $0.8 \mathrm{~dB}$ at all temperatures. 

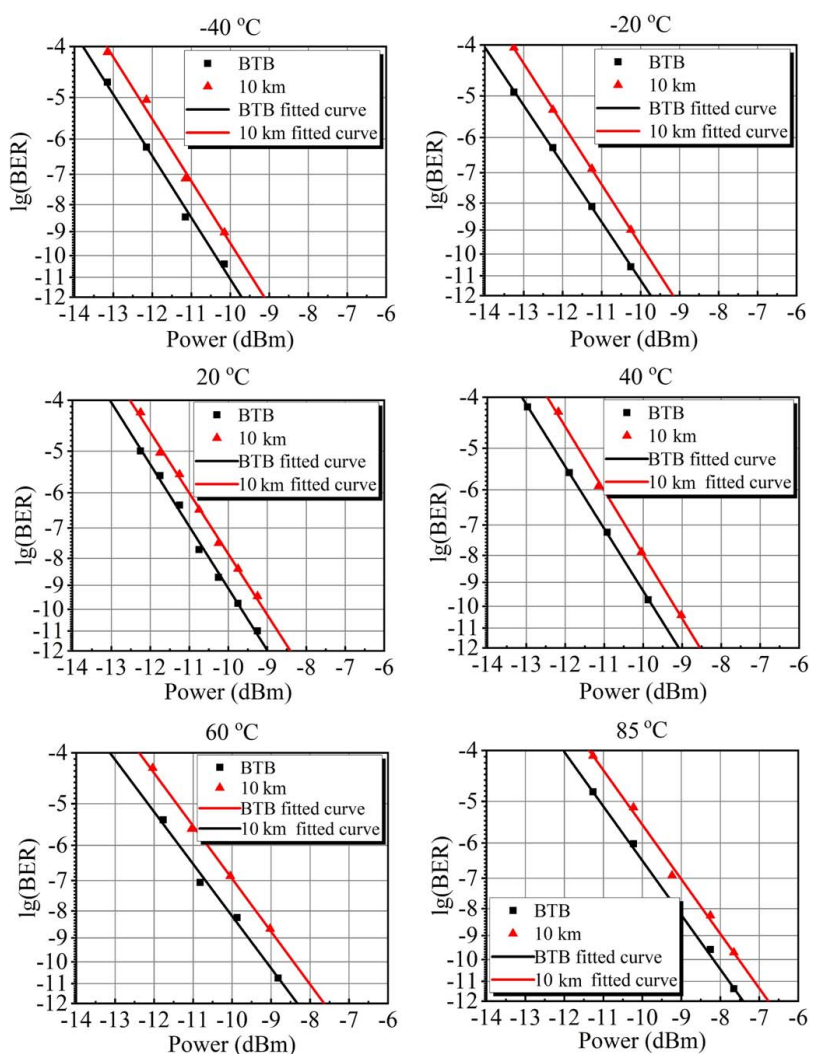

Fig. 7. BER characteristics of the ADR-DFB laser for BTB and $10 \mathrm{~km}$ SMF transmissions over a wide temperature range of $-40-85^{\circ} \mathrm{C}$.

In conclusion, we experimentally demonstrated a $25.8 \mathrm{~Gb} / \mathrm{s}$ NRZ operation over a wide temperature range $\left(-40-85^{\circ} \mathrm{C}\right)$ using the ADR-DFB lasers we developed, which have an unbiased ADR to shorten the active region length. The lasers can achieve additional feedback from ADRs with accurately controlled phase; therefore, high single-mode yield can be obtained. The fabrication of the ADR-DFB laser is simple and mature without special processes. The threshold currents of the ADR-DFB laser are $6 \mathrm{~mA}, 8 \mathrm{~mA}$, and $20 \mathrm{~mA}$ at $-40^{\circ} \mathrm{C}, 20^{\circ} \mathrm{C}$, and $85^{\circ} \mathrm{C}$, respectively. The SMSRs of the ADR-DFB laser is above $50 \mathrm{~dB}$ over a wide temperature range. The ADR-DFB lasers showed clear eye diagrams for BTB configuration and $10 \mathrm{~km} \mathrm{SMF}$ transmission from -40 to $85^{\circ} \mathrm{C}$. Error-free operation over $10 \mathrm{~km}$ SMF transmission and less than $0.8 \mathrm{~dB}$ power penalty were achieved at the same time. Therefore, the ADR-DFB laser with high single-mode yield and simple fabrication is an attractive choice for operating at a high bit rate over a wide temperature range and realizing compact and low-power-consumptive optical transmitters on high-density optical interfaces of multichannel configuration.

\section{References}

1. http://www.ieee802.org/3/ba.

2. https://www.cwdm8-msa.org.

3. Z. Zhang, Y. Liu, J. An, Y. Zhang, Z. Zhao, J. Liu, and N. Zhu, Chin. Opt. Lett. 16, 062501 (2018).

4. H. Wang, L. Guo, W. Zhao, G. Chen, D. Lu, and L. Zhao, Chin. Opt. Lett. 17, 111402 (2019).

5. J. E. Bowers, B. R. Hemenway, A. H. Gnauck, and D. P. Wilt, IEEE J. Quantum Electron. 22, 833 (1986).

6. T. Yamamoto, in Optical Fiber Communication Conference (2012), paper OTH3F5.

7. W. Kobayashi, T. Ito, T. Yamanaka, T. Fujisawa, Y. Shibata, T. Kurosaki, M. Kohtoku, T. Tadokoro, and H. Sanjoh, IEEE J. Sel. Top. Quantum Electron. 19, 1500908 (2013).

8. K. Uomi, in Optical Fiber Communication Conference (2019), paper M2F.1.

9. M. Matsuda, A. Uetake, T. Simoyama, S. Okumura, K. Takabayashi, M. Ekawa, and T. Yamamoto, IEEE J. Sel. Top. Quantum Electron. 21, 241 (2015).

10. K. Nakahara, T. Tsuchiya, T. Kitatani, K. Shinoda, T. Taniguchi, T. Kikawa, M. Aoki, and M. Mukaikubo, IEEE Photon. Technol. Lett. 19, 1436 (2007).

11. T. Tadokoro, W. Kobayashi, T. Fujisawa, T. Yamanaka, and F. Kano, J. Lightwave Technol. 30, 2520 (2012).

12. K. Nakahara, Y. Wakayama, T. Kitatani, T. Taniguchi, T. Fukamachi, Y. Sakuma, and S. Tanaka, in Optical Fiber Communication Conference (2014), paper Th3A.1.

13. Y. Matsui, T. Pham, T. Sudo, G. Carey, B. Young, J. Xu, C. Cole, and C. Roxlo, IEEE J. Lightwave Technol. 34, 2677 (2016).

14. T. Nakajima, A. Nakanishi, N. Sasada, M. Mukaikubo, M. Ebisu, Y. Sekino, S. Hayakawa, K. Okamoto, K. Naoe, and K. Uomi, in International Semiconductor Laser Conference (2018), paper MC4.

15. C.-E. Zah, R. Bhat, B. N. Pathak, F. Favire, W. Lin, C. Wang, N. C. Andreadakis, D. M. Hwang, M. A. Koza, T.-P. Lee, Z. Wang, D. Darby, D. Flanders, and J. J. Hsieh, Quantum. Electron. 30, 511 (1994).

16. P. J. A. Thijs, T. van Dongen, J. J. M. Binsma, and E. J. Jansen, in 8th International Conference on Indium Phosphide and Related Materials (1996), p. 765.

17. G. Zhao, J. Sun, Y. Xi, D. Gao, Q. Lu, and W. Guo, Opt. Express. 24, 10590 (2016).

18. G. Liu, G. Zhao, J. Sun, Y. Xi, D. Gao, Q. Lu, and W. Guo, Opt. Express 26, 29784 (2018).

19. G. Liu, G. Zhao, Q. Lu, and W. Guo, in CLEO: Applications \& Technology (2018), paper JTu2A.22.

20. G. Liu, G. Zhao, Q. Lu, and W. Guo, in Asia Communications and Photonics Conference (2018), p. 1.

21. G. Y. Zhao, G. H. Liu, C. Liu, Q. Y. Lu, and W. H. Guo, in Asia Communications and Photonics Conference (2018), p. 1. 